\title{
Simultaneous optical carrier and radio frequency re-modulation in radio-over-fiber systems employing reflective SOA modulators
}

Kassar, Carvalho; Calabretta, Nicola; Tafur Monroy, Idelfonso

Published in:

The 20th Annual Meeting of the IEEE Lasers and Electro-Optics Society, 2007. LEOS 2007.

Link to article, DOI:

10.1109/LEOS.2007.4382649

Publication date:

2007

Document Version

Publisher's PDF, also known as Version of record

Link back to DTU Orbit

Citation (APA):

Kassar, C., Calabretta, N., \& Tafur Monroy, I. (2007). Simultaneous optical carrier and radio frequency remodulation in radio-over-fiber systems employing reflective SOA modulators. In The 20th Annual Meeting of the IEEE Lasers and Electro-Optics Society, 2007. LEOS 2007. IEEE. https://doi.org/10.1109/LEOS.2007.4382649

\section{General rights}

Copyright and moral rights for the publications made accessible in the public portal are retained by the authors and/or other copyright owners and it is a condition of accessing publications that users recognise and abide by the legal requirements associated with these rights.

- Users may download and print one copy of any publication from the public portal for the purpose of private study or research.

- You may not further distribute the material or use it for any profit-making activity or commercial gain

- You may freely distribute the URL identifying the publication in the public portal 


\title{
Simultaneous optical carrier and radio frequency re-modulation in radio-over-fiber systems employing reflective SOA modulators
}

\author{
Gloria Carvalho Kassar (1, 2), Nicola Calabretta (1), Idelfonso Tafur Monroy (1) \\ 1) COM•DTU, Department of Communications, Optics and Materials, Technical University of Denmark, 2800 Kgs. Lyngby, Denmark \\ 2)Politecnico di Torino, Department of Electronic,Duca degli Abruzzi 24, Torino,Italy (gloria.carvalhokassar@polito.it)
}

\begin{abstract}
We demonstrate an innovative full-duplex radioover-fibre transmission system employing a reflective SOA to perform simultaneous reusing of the optical carrier and data remodulation, thus avoiding the use of local radiofrequency oscillator at the station sites.
\end{abstract}

\section{INTRODUCTION}

As the demand for wireless systems at data rates above 1 Gbit/s grows, radio-over-fibre (RoF) systems for signal distribution of such high bit rate and high radio frequency signals, from the central office (CO) to the remote base stations (BS) are emerging as the most natural solution [1]. In a full-duplex RoF transmission system, information is simultaneously exchanged between the $\mathrm{CO}$ and $\mathrm{BS}$. A ready to be launched wireless signal is transported to the BS, which performs opto-electrical conversion of the downstream signal and delivers it to the antenna. At the same time, the BS converts the received wireless signal to an optical to be transmitted to CO. Generally, the wireless signal received (or transmitted) by the base station antenna is composed of a highfrequency carrier, with an ASK imposed modulation. While most of the proposed RoF systems employ simple radio-front end for the $\mathrm{BS}$, the $\mathrm{CO}$ generally requires a much complex architecture. The $\mathrm{CO}$ includes equipment for the generation of high radiofrequency (RF) carriers and data up-conversion, which imposes stringent requirements on cost and performance as the RF and data rates increases.

Here we present an innovative full-duplex RoF transmission system that avoids the need for a local oscillator and radio frequency mixer for data up-conversion, greatly simplifying the CO. The basic idea is to reuse at the $\mathrm{CO}$ both the RF carrier and the optical carrier coming from the BS for downstream communication. To perform this operation, we introduce a reflective semiconductor optical amplifier (R-SOA) at the $\mathrm{CO}$ that all-optically acts simultaneously as high-pass filter, erasing the $1.25 \mathrm{Gbit} / \mathrm{s}$ ASK upstream data modulation, and as intensity optical modulator to impose another $1.25 \mathrm{Gbit} / \mathrm{s}$ ASK signal for downstream communication.

\section{PRINCIPLE OF OPERATION}

The schematic of the full-duplex RoF transmission system is presented in Figure 1. It consists of a base and a central radio station connected by means of an optical fiber link. The antenna at the BS receives a $15 \mathrm{GHz} \mathrm{RF}, 1.25 \mathrm{Gbit} / \mathrm{s}$ ASK modulated. We consider the case of the recently proposed alloptical half-wave rectified RoF system [2], where the RF signal is intensity modulated onto an optical carrier by means of an electro-absorption modulator (EAM) to be transported to

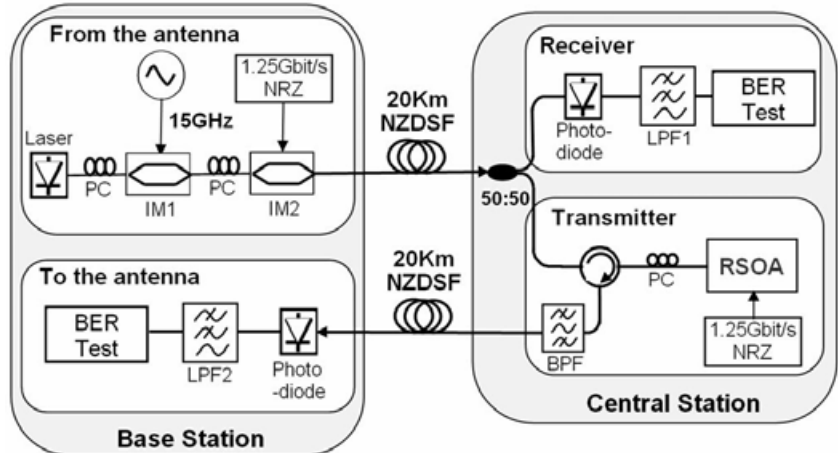

Figure 1. Experimental setup of the full-duplex RoF transmission system

the CO. The difference with a conventional RoF systems lies in that due to the selected operation point at the EAM, a half-wave rectified version of the received wireless signal is transported instead of the intact received signal from the antenna. At the $\mathrm{CO}$, the signal is split by a 50:50 optical coupler. One copy of the signal is received by a low speed photo detector followed by a low-pass filter (LPF), which operates as an envelope detector. The other copy of the signal is fed via an optical circulator into an R-SOA device. If the optical power of the signal fed into the R-SOA is sufficiently high to saturate the gain of the SOA, it acts as a high-pass filter with a cut-off frequency determined by the carrier response time [3]. The high frequency components of the optical signal are equally amplified while the low frequency imposed intensity modulation is removed and therefore the high frequency microwave carrier is equalized as shown in figure $2 b$. At the same time, the R-SOA operates as an optical intensity modulator [4] to impose the ASK modulated downstream data (see figure $2 \mathrm{c}$ ) information to be transported to the BS. The value of the modulation index can be controlled by varying the bias voltage of the R-SOA. Thus, the optical output signal of the R-SOA output consists of the (equalized) microwave carrier modulated by the ASK downstream data that is subsequently transmitted through the optical link to the BS. At the BS, a photo detector converts the incoming optical to the electrical domain to be delivered to the antenna transmitter.

\section{EXPERIMENTS}

In Figure 1 is shown the experimental set-up to generate, a half-wave rectified, ASK modulated, upstream signal, received from the antenna. This block, marks as base station in Figure 1, is composed of light source at $1549.6 \mathrm{~nm}$, followed by a MachZehnder optical intensity modulator (IM1) driven by a $15 \mathrm{GHz}$ sinusoidal signal (representing the microwave carrier). The ASK upstream data information, with a PRBS length of $2^{7}-1$, at $1.25 \mathrm{Gbit} / \mathrm{s}$ is imposed into the radio frequency carrier by 
means of a second Mach-Zehnder optical intensity modulator (IM2). The modulation index of the data information was set to be $10 \%$. The resulting upstream optical signal is shown in figure $2 \mathrm{a}$. This signal was transmitted through a $20 \mathrm{~km}$ nonzero-dispersion fiber link with a total attenuation of $4.5 \mathrm{~dB}$ and a chromatic dispersion parameter of $5 \mathrm{ps} / \mathrm{nm} / \mathrm{km}$. The use of NZD fiber prevents the use of dispersion compensation especially if radio frequency carrier above $10 \mathrm{GHz}$ will be employed. At the $\mathrm{CO}$, a $3 \mathrm{~dB}$ coupler is used to send a copy of the upstream to the central station receiver, consisting of a low speed photo detector followed by an electrical LPF with bandwidth of $1.8 \mathrm{GHz}$. The other copy of the upstream signal enters the R-SOA via an optical circulator. A polarization controller was used to optimize the state of polarization of the input signal to the R-SOA. The average optical power of the upstream signal at the input of the RSOA was $-8 \mathrm{dBm}$ that guarantees the R-SOA operates in the saturation regime. Figure $2 b$ shows a snapshot of the equalized $\mathrm{RF}$ carrier, no downstream modulation is applied to the R-SOA. It can be clearly observed that the upstream ASK modulation has been removed by the high pass filter property of the R-SOA.

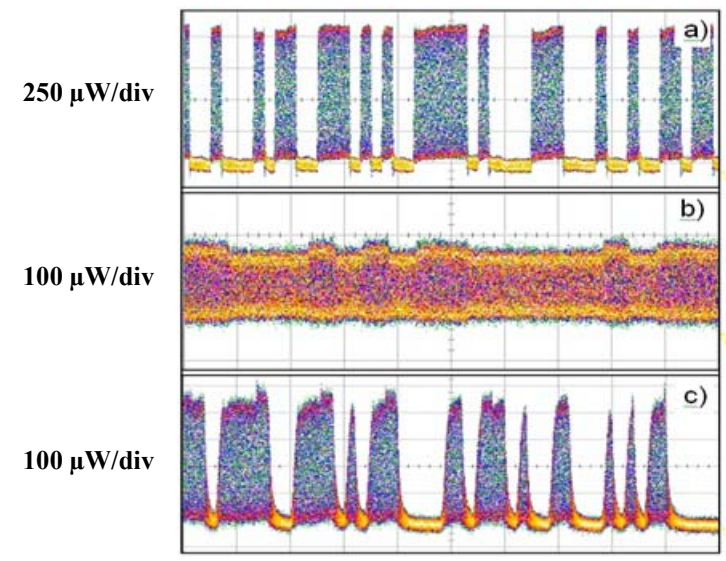

Figure 2: Measured traces. a) Optical upstream signal, $10 \%$ modulation index b) Equalized microwave carrier after the RSOA (no downstream modulation was applied). c) Optical downstream signal by reusing the microwave carrier at the RSOA output. Modulation index was $10 \%$. Time scale was 2 ns/div.

The 1.25 Gbit/s ASK $2^{7}-1$ PRBS upstream signal was imposed into the optical and equalized carrier by modulating the R-SOA driving current. A modulation index of $10 \%$ was obtained by adjusting the bias voltage applied to the R-SOA. The optical circulator was used to separate the down and upstream signal and an optical bandpass filter was used to reject the broad amplified spontaneous emission (ASE) noise of the RSOA. Figure 2c shows the obtained optical downstream signal at the output of the R-SOA. The downstream signal was then transmitted through $20 \mathrm{~km}$ NZDF fiber link to the BS, where it was converted into the electrical domain by using a photodetector, ready to be fed to the transmitter antenna.

The performance of the full-duplex system was determined by measuring the bit-error rate (BER). In figure 3, the measured BER curves of the downstream and upstream data with modulation index of $10 \%$ versus the average received optical power is reported. We can observe that no appreciable power penalty is measured between the back-to-back and the upstream data signal after $20 \mathrm{~km}$ NZDS fibre transmission, as expected due to the low accumulated chromatic dispersion. For the downstream signal, at the output of the RSOA, a $0.2 \mathrm{~dB}$ of power penalty for the receiver sensitivity at a BER level of $10^{-9}$ is observed. When comparing the BER curve for the downstream signal at the $\mathrm{CO}$, after the $20 \mathrm{~km}$ of fiber, an additional power penalty of $0.5 \mathrm{~dB}$ was found. We also report in the insets of figure 3 the eye diagrams of the received upstream and downstream data signals. The eye diagram of the downstream signal presents slower rising and falling times due to the limited modulation bandwidth of the R-SOA.

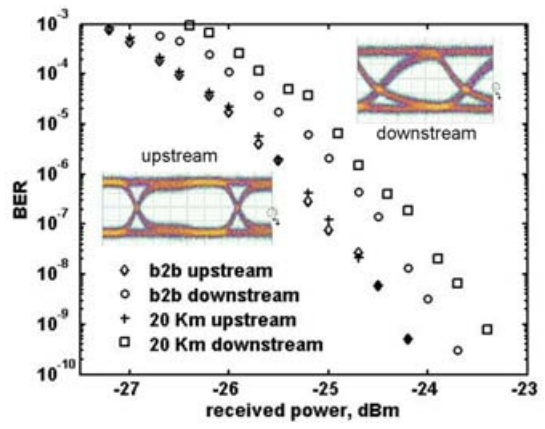

Figure 3: BER measurements vs. received power. The modulation depth was $10 \%$ either for the downstream and the upstream signal.

\section{CONCLUSION}

Error-free operation of the proposed full-duplex transmission system employing an R-SOA at central office to reuse the upstream optical and radio frequency carrier was successfully demonstrated. Limited power penalty of $0.7 \mathrm{~dB}$ was measured for the re-modulated downstream signal mainly due to the limited modulation bandwidth of the R-SOA. Alternative reflective modulator devices based on SOA and electroabsorber modulator can be used to achieve operation at higher data rate [5]. The proposed scheme re-utilizes the upstream optical carrier and can operate even at higher microwave carrier frequency than the $15 \mathrm{GHz}$ used in the present proof-ofprinciple which in combination with NZD shifted fibres for the fiber link prevent the need for dispersion compensation modules for higher carrier frequency RoF transmission systems.

\section{REFERENCES}

[1] T. Nakasyotani et al, 'Wavelength-division-multiplexed millimeterwaveband radio-on-fiber system using a supercontinuum light source', Journal of Lightwave Technology, vol. 24, 404-410, 2006.

[2] I. Tafur Monroy et al, All-optical envelope detection for wireless photonic communication, accepted for oral presentation at ECOC 2007 conference.

[3] K. Sato and H. Toba, 'Reduction of mode partition noise by using semiconductor optical amplifier,' IEEE Journal of Selected Topics in Quantum Electronics, vol. 7, pp 328-333, 2001.

[4] W. Lee et al., 'Bidirectional WDM-PON based on gain-saturated reflective semiconductor optical amplifiers,' IEEE Photonics Technology Letters, vol. 17, pp. 2460-2462, 2005.

[5] I. Tafur Monroy et al.,'Monolithically integrated reflective SOA-EAM carrier re-modulator for broadband access nodes,' Optics Express, vol. 14, pp. 8060-8064, 2006. 